\title{
EFFECT OF NON-METALLIC INCLUSIONS OF RAIL STEEL ON WELDED JOINT FORMATION
}

\author{
S.I. KUCHUK-YATSENKO, V.I. SHVETS, A.V. DIDKOVSKY and E.V. ANTIPIN \\ E.O. Paton Electric Welding Institute, NASU \\ 11 Kazimir Malevich Str., 03680, Kiev, Ukraine. E-mail: office@paton.kiev.ua
}

\begin{abstract}
On the railways of Ukraine since 2012 the laying of high-strength rails of steel grade K76F of Company «MK Azovstal» production, as well as rails produced in Russia, in tracks began. For this purpose at PWI the technology for flash-butt welding of high-strength rails of different production was developed, providing the values of strength and ductility of welded joints required according to the Technical Specifications. In the process of industrial implementation of technology for welding the high-strength rails by the rail welding enterprises of Ukraine a large amount of information was gained on the results of complex application of in-process control with non-destructive and destructive testing methods. It was established that the formation of metal structure in the joint zone alongside with energy input has a significant influence on the composition and distribution of non-metallic inclusions in the base metal of welded rails. The type and the structure of defects are largely determined by the composition of non-metallic inclusions. This effect is manifested in different degrees during changes in energy input in the process of welding. 5 Ref., 3 Tables, 8 Figures.
\end{abstract}

Keywords : flash-butt welding, flashing, rails, high-strength rails, pulsed flashing, defects in rails, non-metallic inclusions, dull spots, quality control, continuous track

At PWI the technology of flash-butt welding of highstrength rails of different production was developed, providing the values of strength and ductility of welded joints required according to TS. It is based on the method with pulsed flashing (PF) [1], allowing joining the high-strength rails with their minimal softening and preservation of the required ductile properties. As compared to the known technologies for welding rails, the developed technology requires $1.5-2$ times lower energy input.

A stable reproduction of technological process requires precise control of energy input, that is provided by the system of automatic control of flashing process using the system for in-process control the welding parameters. At the same time, the maximum admissible deviations from the preset temperature field were established, that provide the optimal conditions for joint formation [2].

In the process of industrial implementation of the technology for welding the high-strength rails by rail welding enterprises (RWE) of Ukraine a large volume of information was gained on the results of complex application of in-process control with non-destructive and destructive testing methods. It was established that the formation of metal structure in the joining area alongside with energy input has a significant influence on the composition and distribution of non-metallic inclusions (NMI) in the base rails metal. This effect is manifested in different degrees during changes in energy input in the process of welding.

The aim of the investigations was to study the effect of NMI in the rail steel on formation of the structure of welds of high-strength rails.

To carry out investigations at the RWE the specimens of high-strength rails of different manufacturers were selected. The selection was carried out mainly from the batches of rails, during welding of which the unstable values of quality of welds were observed.

The chemical composition and mechanical properties of the investigated batches of specimens are shown in Table 1. The content of impurities and alloying elements in them corresponds to the certification documents.

Table 1. Chemical composition of rail steel investigated, wt.\%

\begin{tabular}{|c|c|c|c|c|c|c|c|}
\hline \multirow{2}{*}{ Steel grade } & \multicolumn{9}{|c|}{ Chemical composition, \% } & $\mathrm{A}$ & $\mathrm{Al}$ & $\mathrm{S}$ \\
\cline { 2 - 8 } & $\mathrm{C}$ & $\mathrm{Mn}$ & $\mathrm{Si}$ & $\mathrm{V}$ & 0.035 & 0.015 & 0.045 \\
\hline K76F (Ukraine) & $0.71-0.82$ & $0.80-1.30$ & $0.25-0.45$ & $0.03-0.07$ & 0.035 & 0.02 & 0.03 \\
\hline
\end{tabular}




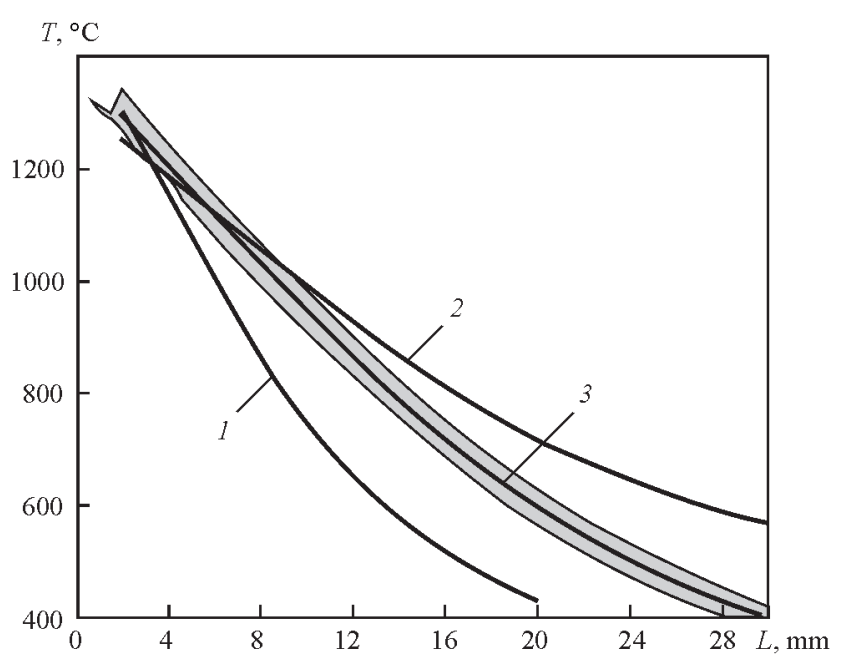

Figure 1. Temperature distribution in HAZ before upsetting during pulsed FBW of rails R65 at extremely low (1), extremely high (2) and optumal (3) heat input: $1-t_{\mathrm{w}}=30-40 ; 2-110$ $120 ; 3-70-80 \mathrm{~s}$

The welding of specimens of high-strength rails was carried out in stationary machine K1000, which is operated at the RWE of Ukraine. The welding programs were used the same as in the industrial conditions. At the same time, the modes with extremely low (Figure 1, mode 1), extremely high (mode 2 ) and optimal (mode 3) admissible heat inputs were preset.

The welded joints of all the batches were subjected to non-destructive ultrasonic testing and tested also for static bending in accordance with the accepted procedures. A part of the joints was investigated using the methods of metallographic analysis in optical microscope «Neophot-32» and in microanalyzer JAMP9500F.

In Table 2 the results of tests of welded joints of rails on static transverse bending are shown, as well as the requirements of standard documents are given for comparison. According to the test results it can be said that the best values were obtained in welding at mode 3 and within its limits, and in welding at modes 1 and 2 the stable results were not obtained.

Here in both cases, the lacks of separate values of strength and ductility are recorded. In the fractures of such joints the defects are observed, determined as «dull spots» (DS). They are distinguished by undeveloped relief on the fracture surface and characterized by the grey color. Their total area is regulated by normative documents [3]. According to our investigations, in the microstructure of DS the numerous fused-type inclusions (Figure 2) are present on the background of mostly pit matrix fracture (single cleavage facets are found).

According to the results of X-ray microanalysis the basis of inclusions consists of manganese silicates. At negligible iron content their composition may include such active elements as aluminum, calcium, titani-

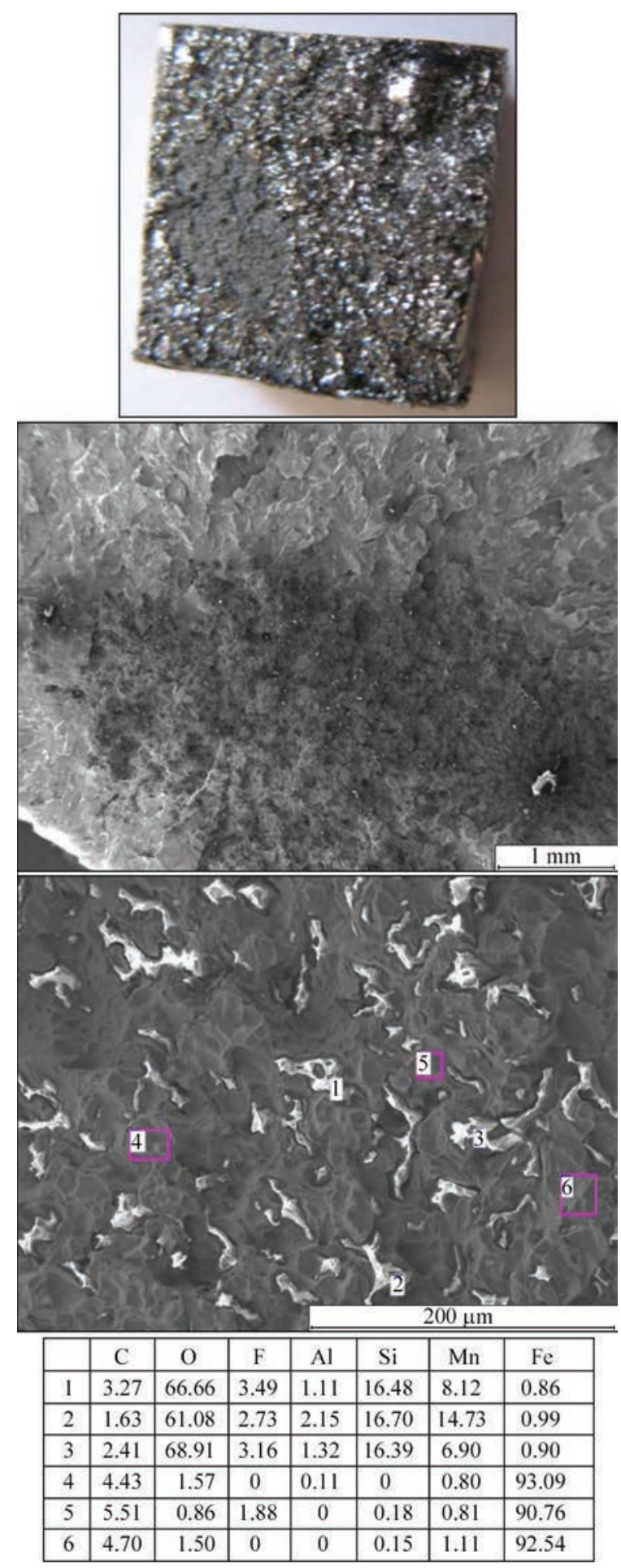

Figure 2. Silicate «dull spots» on the fracture of welded joints and results of analysis of rail metal of «Azovstal» production

um and magnesium. The size of inclusions of about $10 \mu \mathrm{m}$ gives grounds to consider that the observed cluster of silicates is formed as a result of a large inclusion fragmentation during upsetting.

Alongside with the traditional silicate DS in the fractures of rails of steel K76F of «Azovstal» production, fractured during the tests on bending along the base metal and in HAZ, the clearly contoured DS of other nature were observed (Figure 3). In definite cases their area reached tens of square millimeters. 


\section{FASHBUTTWELDING}
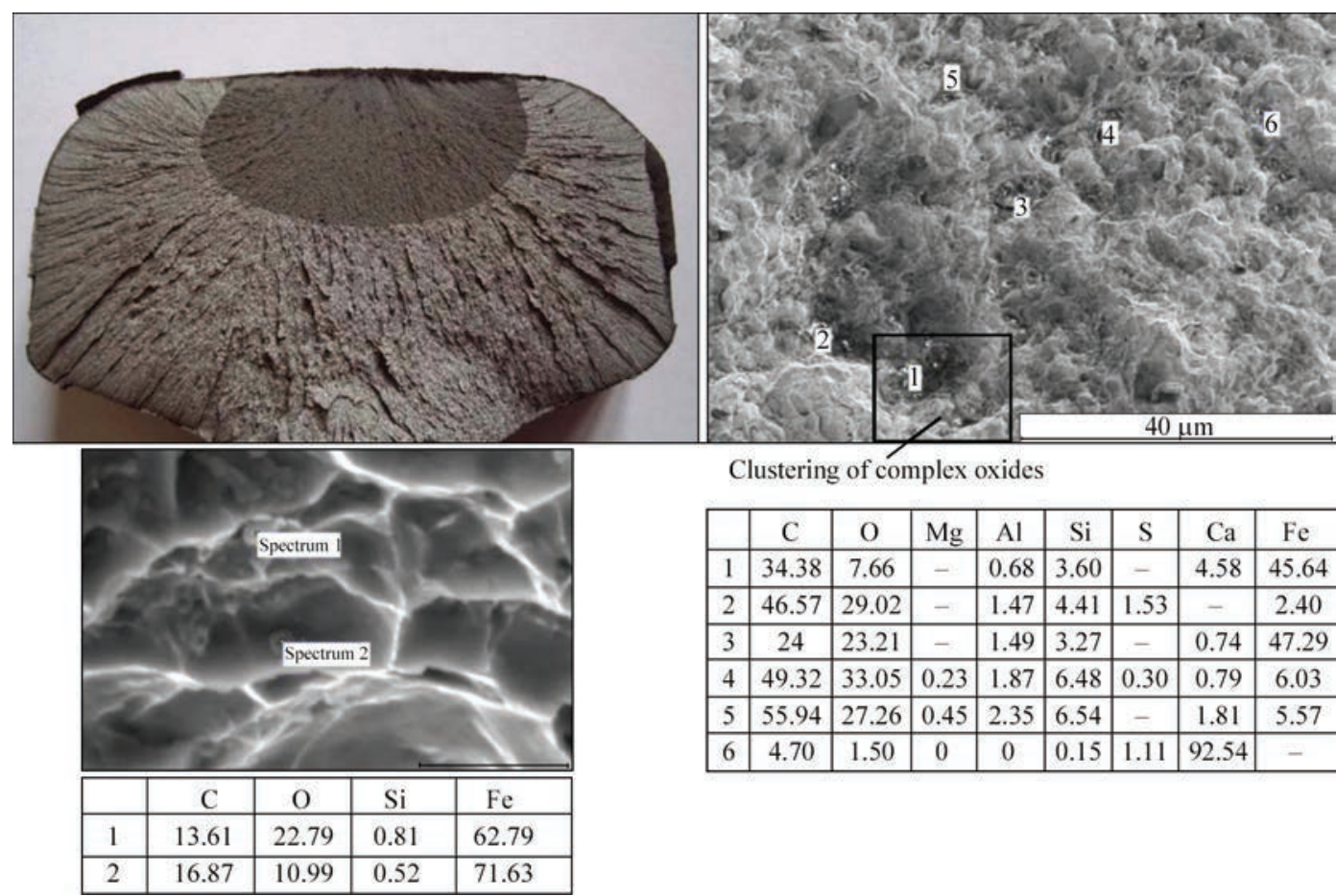

Clustering of complex oxides

\begin{tabular}{|c|c|c|c|c|c|c|c|c}
\hline & $\mathrm{C}$ & $\mathrm{O}$ & $\mathrm{Mg}$ & $\mathrm{Al}$ & $\mathrm{Si}$ & $\mathrm{S}$ & $\mathrm{Ca}$ & $\mathrm{Fe}$ \\
\hline 1 & 34.38 & 7.66 & - & 0.68 & 3.60 & - & 4.58 & 45.64 \\
\hline 2 & 46.57 & 29.02 & - & 1.47 & 4.41 & 1.53 & - & 2.40 \\
\hline 3 & 24 & 23.21 & - & 1.49 & 3.27 & - & 0.74 & 47.29 \\
\hline 4 & 49.32 & 33.05 & 0.23 & 1.87 & 6.48 & 0.30 & 0.79 & 6.03 \\
\hline 5 & 55.94 & 27.26 & 0.45 & 2.35 & 6.54 & - & 1.81 & 5.57 \\
\hline 6 & 4.70 & 1.50 & 0 & 0 & 0.15 & 1.11 & 92.54 & - \\
\hline
\end{tabular}

Figure 3. Oxide «dull spots» on the fracture of rails of «Azovstal» production

Table 2. Results of tests of rails of steels $\mathrm{K} 76 \mathrm{~F}$ and $76 \mathrm{~F}$ on bending

\begin{tabular}{|c|c|c|c|c|}
\hline \multirow{3}{*}{$\begin{array}{l}\text { Number } \\
\text { of mode }\end{array}$} & Standard and steel grade & Fracture load, $\mathrm{kN}$ & Bending deflection, $\mathrm{mm}$ & Note \\
\hline & Ukraine & 160 & $\geq 30$ & TU U 24.1-40075815-002:2016 \\
\hline & Russia & 210 & $\geq 27$ & STO RZhD 1.08.002-2009 \\
\hline 1 & $\mathrm{~K} 76 \mathrm{~F}$ & $\frac{1750-2000}{1950}$ & $\frac{25-35}{28}$ & PF \\
\hline 1 & $76 \mathrm{~F}$ & $\frac{1750-2300}{1950}$ & $\frac{12-35}{28}$ & Same \\
\hline 2 & $\mathrm{~K} 76 \mathrm{~F}$ & $\frac{1800-2000}{1900}$ & $\frac{14-30}{19}$ & $»$ \\
\hline 2 & $76 \mathrm{~F}$ & $\frac{1700-2300}{2000}$ & $\frac{12-32}{21}$ & $»$ \\
\hline 2 & $\mathrm{~K} 76 \mathrm{~F}$ & $\frac{2000-2300}{2150}$ & $\frac{35-45}{38}$ & $»$ \\
\hline 3 & $76 \mathrm{~F}$ & $\frac{2300-2600}{2450}$ & $\frac{30-46}{38}$ & $»$ \\
\hline
\end{tabular}

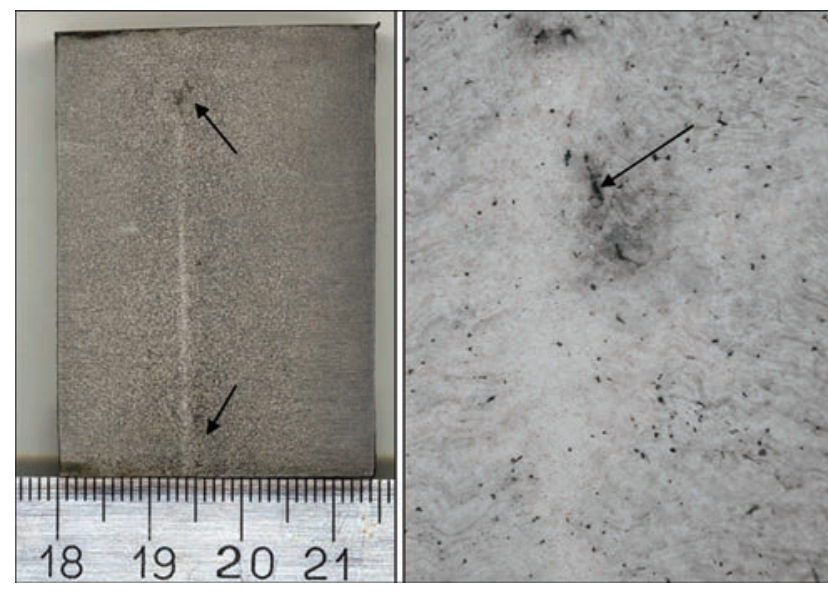

Figure 4. Microcracks in macrostructure $(\times 25)$ of welded joints of rail steel $76 \mathrm{~F}$

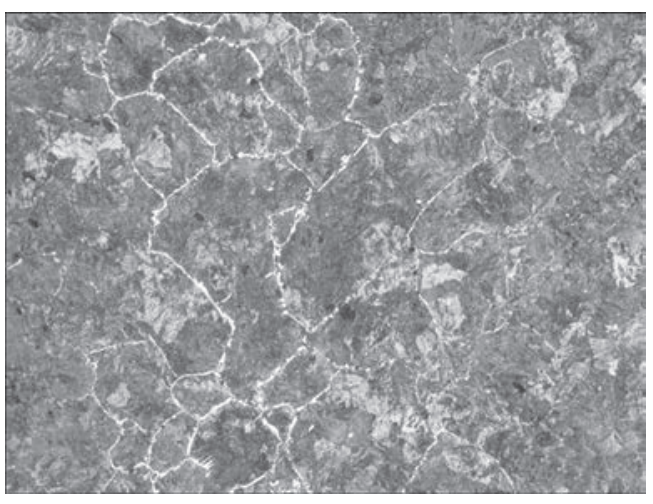

Figure 5. Microstructure $(\times 100)$ of joint of rails of $76 \mathrm{~F}$ steel welded at mode 2 with extremely high heat input 


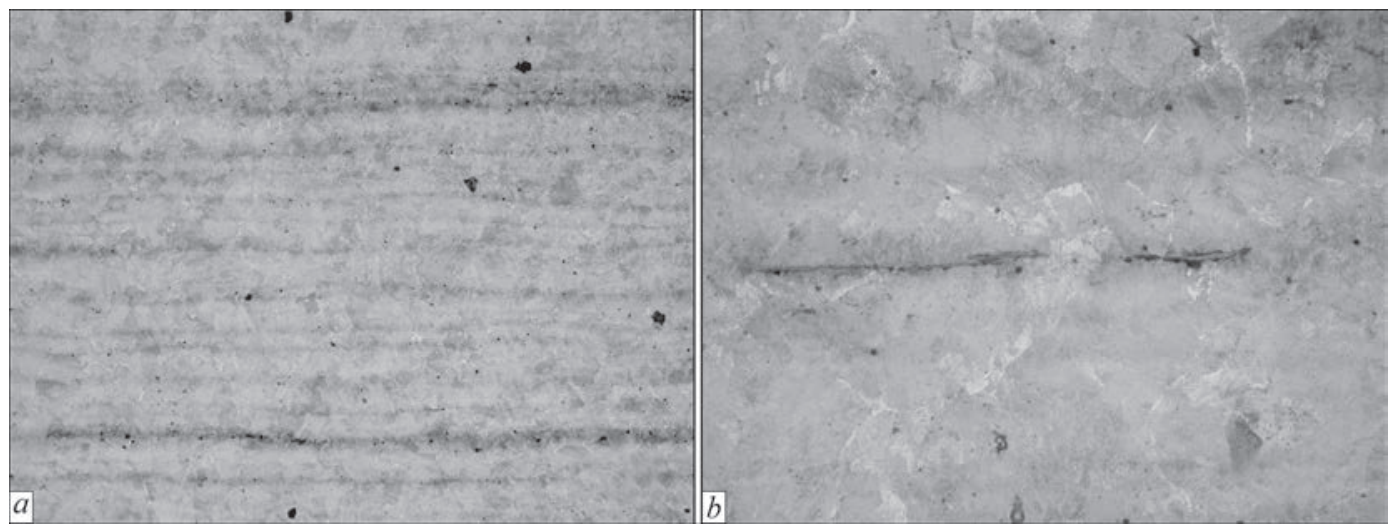

Figure 6. Inclusions of sulfides in the rails metal of steel 76F revealed by etching in sodium picrate: $a-\times 100 ; b-\times 400$

Fine metallographic examinations showed that the nature of fracture in the area of spots is also of pit type. However, in the pits not silicates are present, but iron oxides of the size smaller than several tenths of micron. It should be noted that within the spot the clusters of larger inclusions of complex oxides of aluminum, calcium, silicon of the size of several microns were also observed.

Obviously, these spots are the result of formation of low-melting films in the metal, the base of which is iron oxide. Such spots on the fracture surface, unlike the silicate ones, can be classified as oxide DS. Due to a very small film thickness to detect them in the rail metal using ultrasonic testing is problematic, that complicates the preliminary rejection of rails.

The increase in heat input during welding leads to decrease in test values of investigated steels. This is caused, first of all, by increase in grain size in the middle part of the weld and development of the process of ferrite precipitation along the boundaries of primary austenite grains along the joining line.

In the specimens of rails of steel $76 \mathrm{~F}$ welded at mode 2 , the metal heterogeneity was detected using ultrasonic testing, and the subsequent analysis of macrostructure showed that the observed heterogeneity is the result of crack initiation (Figure 4).

The microstructure of weld metal is homogeneously sorbite (Figure 5). Along the joining line a layer with a ferrite fringing of boundaries of the primary austenitic grains is observed. The width of this layer is about $500 \mu \mathrm{m}$. According to ASTM the size of primary austenitic grains corresponds to $1-2$. The width of normalization area of welded joint is about $40 \mathrm{~mm}$.

The microstructure of base rail metal is sorbite-pearlite. In the base metal the numerous sulfides (Fe, Mn)S are present in the form of chains of small globules and lenticular inclusions, extended along the direction of rolling (see Figure 5 and Table 2). Separate, randomly scattered large sulfides of irregular shape were also encountered. Lenticular sulfides, as is known, are enriched with iron, more ductile and are the product of hot deformation during rolling [4].

In the thermal deformation conditions of welding the sulfide inclusions are stretched along the deformation bands. In the near-contact layer the activation of diffusion processes leads to violation of linearity of their location and coagulation (Figures 6 and 7).

The microcracks, detected in the near-contact layer, are adjacent to the sulfide inclusions (Figure 8). The iron content in these sulfides is significantly higher than that in the lenticular inclusions of base metal (80-85 versus $50-60 \mathrm{wt} . \%$ ), that is the evidence of active interaction with the iron matrix.

In system $\mathrm{FeS}-\mathrm{MnS}$ the eutectics with melting temperature of $1164{ }^{\circ} \mathrm{C}$ exists. At the contact boundary of inclusions of manganese sulfides with iron matrix the formation of the eutectic melt is possible during technological heating. The intensification of this process leads to increase in the melt volume and its spreading along the structural boundaries. In the literature this phenomenon is defined as a tough-brittle transition at the near-solidus temperatures [5], which is not a natural property of steel and is determined by the presence of impurity elements of metallurgical origin, mainly sulfur, phosphorus and oxygen.

Cracking of the joint metal of rails along the eutectic interlayers, forming in the near-contact layer, can occur both during cooling, as well as under the load in the process of operation. It has a risk that the joints of rails, which passed testing, can be fractured being laid in track.

The crack propagation is significantly influenced by metal deformation in the near-contact layer during

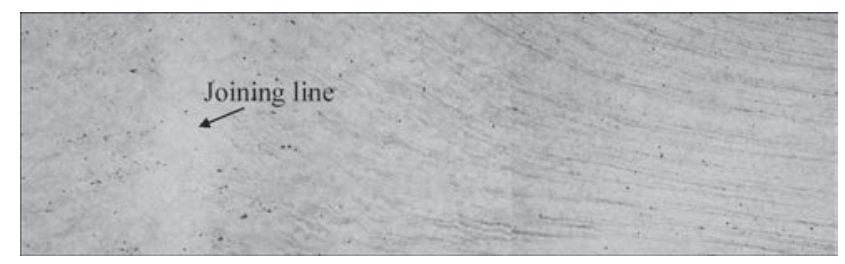

Figure 7. Transformation of microstructure of welded joint of $76 \mathrm{~F}$ rail steel 


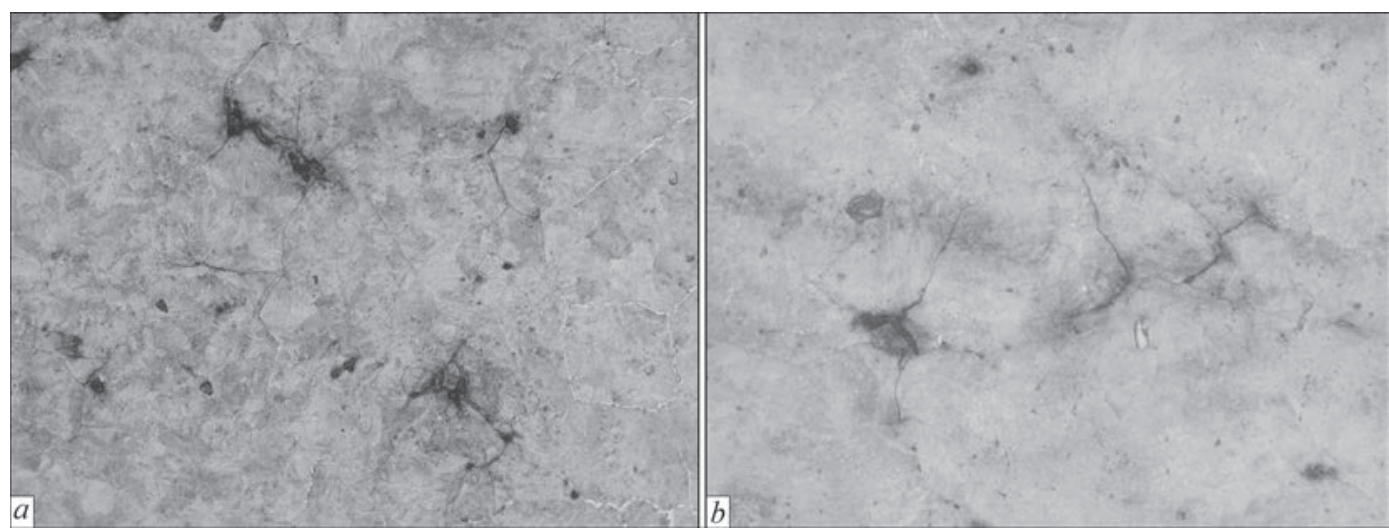

Figure 8. Microcracks in the near-contact layer of welded joints of steel 76F rails: $a-\times 100 ; b-\times 400$

Table 3. Results of X-ray spectral microanalysis of chemical composition of inclusions in the rail metal

\begin{tabular}{|l|c|c|c|c|c|}
\hline \multirow{2}{*}{ Structural component } & \multicolumn{3}{c|}{ Elements, wt. \% } & Mn & Fe \\
\cline { 2 - 7 } & $\mathrm{Al}$ & $\mathrm{Si}$ & 0 & 0.798 & 98.726 \\
\hline Matrix & 0.341 & 0.135 & 18.511 & 30.872 & 49.726 \\
\hline Inclusions in BM & 0.530 & 0.361 & 15.254 & 25.738 & 58.630 \\
\hline Inclusions in BM & 0.321 & 0.049 & 16.312 & 27.269 & 55.852 \\
\hline Inclusions in BM & 0.358 & 0.209 & 3.751 & 7.657 & 87.433 \\
\hline Inclusions near the joining line & 0.729 & 0.430 & 3.211 & 6.336 & 89.712 \\
\hline Inclusions near the joining line & 0.278 & 0.463 & & \\
\hline
\end{tabular}

upsetting. The rolled bands enriched with inclusions of sulfides (Table 3 ) are bent and orient the weakened region into the most unfavorable direction in relation to the loads, to which the rail joint is subjected.

The more severe heating mode results in immunization of the process of sulfides transformation and its retard at the stage of coagulation before spreading of eutectic melt along the grain boundaries. It allowed avoiding the cracking of metal in the joints, welded at modes 1 and 3 .

\section{Conclusions}

1. The presence of NMI in the rail steel can significantly effect the formation of defects in welding zone. The type and the structure of defects are largely determined by the NMI composition.

2. The oxide inclusions, concentrated in the rolled bands, are carried away to the weld zone, and under the deformation conditions forming clusters, are lined up in the most unfavorable direction in relation to the loads, to which the rail is subjected.

3. The energy input in welding influences the formation of defects. With increased energy input in the near-contact zone on the basis of manganese sulfides the low-melting eutectics are formed, propagating along the grain boundaries and causing danger of microcracks formation.

1. Kuchuk-Yatsenko, S.I., Lebedev, V.Kh. (1976) Continuous flash-butt welding. Kiev: Naukova Dumka.

2. Kuchuk-Yatsenko, S.I., Krivenko, V.G., Didkovsky, A.V. et al. (2012) Technology and new generation of equipment for flash butt welding of advanced high-strength rails for construction and reconstruction of high-speed railway lines. The Paton Welding J., 6, 22-26.

3. TU U 27.1-40081293-002:2016: New welded rails for railroads. Dnipropetrovsk: Ukrzaliznytsya.

4. Dementiev, V.P. (2002) Liquation in R65 profile of rail steel. Izvestiya Vuzov. Chyorn. Metallurgiya, 10, 1-9.

5. Zabilsky, V.V., Nikonova, R.M. (2005) Tought-brittle transition in steels at near-solidus temperatures. Mechanism of grain boundary embrittlement. FMM, Vol. 99, Issue 3, 1-9.

Received 16.05.2016 